\title{
Features of Application of Relevant Approach in Decision Making to Participate in Tender for Assessment of Land
}

Klychova G.S.

Kazan State Agrarian University, Karl Marx str., 65, Kazan, 420015

Safiullin L.N.

Kazan Federal University, Kazan, 420008, Russia

Klychova A.S.

Kazan State Agrarian University, Karl Marx str., 65, Kazan, 420015

Doi:10.5901/mjss.2014.v5n18p183

\section{Abstract}

The paper describes the features of relevant approach for decision making to participate (or not participate) in a tender for appraisment of land. The basis of this approach is the following: the greater is the number of non-won tenders, the greater is the amount of irrelevant costs, and company operations are less effective. Thus, the approach to use relevant and non-relevant indicators should be applied not to a particular tender, but at once to a group of tenders. This transforms the traditional notion of relevance and suggests that in certain situations the irrelevant costs are unchanged, and the presence of a negative relevant result, as to one of the orders, does not lead to the automatic rejection of its execution.

Keywords: land, assessment, relevant costs, irrelevant costs, tender.

\section{Introduction}

The additional possibility of formation of new orders for appraisement of land is taking part in the auctions conducted on the basis of competition between firms-applicants. Thus, for solving management problems facing the management of appraising firms, and for fair pricing of tender contracts, it is desirable, in our view, to use the relevant approach in management decision-making. Since the customer himself makes decision to place orders, the traditional for management accounting approach to formation of relevant costs needs rethinking.

First, it is necessary to remember what relevant costs are. The nature of these costs, in our opinion, mostly well has been explained by K. Drury (1998) in his book "Introduction to management and cost accounting." It was written there: "When making a decision, only those revenues and expenses are taken into account, the value of which depends on the decision made" [1, 4]. Such expenses and revenues are called relevant ones, i.e. taken into account. Accordingly, to irrelevant expenses (and revenues) are related those, the value of which is independent of choice of this or that option, that is, remains unchanged. According to the classical in management accounting representation the values of irrelevant indicators can be ignored. Let us consider the following example.

The approach set out in the example is true, but only under the condition of ignoring the relationship between the tenders. At the same time, the activities of the firm in which decisions are made on a regular basis to participate in the tenders, even on the basis of partial coverage of irrelevant costs can seriously be impaired by reducing the difference between revenues received by the organization for the period, and uncovered irrelevant costs for the same period. In other words, the greater is the number of non-won tenders, the greater is the amount of irrelevant costs, and operations company - less effective. This is especially true for newly established organizations traditionally having difficulties in finding regular customers and orders, as well as for all organizations operating in the crisis period, when the number of tenders is limited, so the owners are forced to take risks by setting low prices in the hope that a subsequent tender will be won and cover a part of non-return costs. Thus, in our view, the approach to the use of relevant and irrelevant indicators should be applied not to a particular tender, and once to a group of tenders, which expands the field of analysis and allows us to make more objective management decisions $[2,5,7]$. 
The above approach to group analysis of tenders transforms traditional ideas regarding interpretation of the results based on relevance and suggests that in certain situations irrelevant costs are changed, and the relevant negative result on one of the orders does not lead to automatic rejection of its execution. Here is the example.

The management of "Appraiser" JSC organization applies for participation at once in two tenders, though internal resources of the organization (number of appraisers, amount of current assets, etc.) are sufficient for only one order. Thus, the management hopes, on the one hand, to increase the chances of getting the order, on the other hand - if it wins one of the tenders - supposes to abandon the other tender, considering the applications for which will take longer time. In such circumstances, the formation of irrelevant information, to exclude it from analysis, should be done not according to one, but to two orders, with either one or none of the tenders will be won. Let us consider both.

Table 1: Effectiveness analysis of allocation of orders to participate in tenders, which is performed on the basis of relevant approach in management

\begin{tabular}{|c|c|c|c|c|}
\hline \multirow[b]{2}{*}{ Indicators } & \multicolumn{2}{|c|}{ tender № 1, th. rub. } & \multicolumn{2}{|c|}{ Tender number 2 , th. rub. } \\
\hline & Relevant & Irrelevant & Relevant & Irrelevant \\
\hline Cost item 1 & $\sum p^{1}$ & - & $\sum p^{2}$ & - \\
\hline Cost item 2 & - & $\sum_{H^{1}}$ & - & $\sum \mathrm{H}^{2}$ \\
\hline Cost item 3 & - & $\sum_{H^{1}}$ & - & $\sum \mathrm{H}^{2}$ \\
\hline Cost item 4 - irrelevant costs of order 1 (see point 2) & $\mathrm{x}$ & $\mathrm{x}$ & - & $2 \sum_{H^{1}}$ \\
\hline 2. Total costs & $\sum p^{1}$ & $2 \sum_{H^{1}}$ & $\sum p^{2}$ & $4 \sum H^{1,2}$ \\
\hline result & \multicolumn{2}{|c|}{ Abandonment of the tender } & \multicolumn{2}{|c|}{ Winning the tender } \\
\hline
\end{tabular}

Let us consider a situation, where "Appraiser" JSC company does not win in any of the tenders, or for any reason withdraws both the applications, either on the results of analysis given in Table 1 initially refuses to participate in tenders. In these cases, it is impossible to compensate irrelevant costs, therefore their value for each of the tenders remain unchanged - at the level of $2 \Sigma_{\mathrm{H}}$. Thus, irrelevant costs behave according to classical approach to the definition of relevance essence. But the principle of unchangability of irrelevant costs ceases to operate at the time of appearance of the new (third) tender, which can compensate the earlier costs in amount of $4 \sum \mathrm{H}^{1,2}$, and cover the own relevant and irrelevant costs.

Thus, as in the previous situation, we are talking about the need to win the tender, the revenue from implementation of which will eventually pay back all the earlier costs. From this perspective, it can be stated that there is a critical amount of accumulation of irrelevant costs, even when the desired order in the most ideal conditions of implementation will not be able to offset all previously made costs, for the accumulation of irrelevant costs is the trend that cannot be reversed by one order. To track this trend, one can apply the formula:

$$
\mathrm{K}_{\mathrm{H} 3}=\sum_{\mathrm{H}}:\left(\sum_{\mathrm{p}}+\sum_{\mathrm{H}}\right) \text {, }
$$

(1)

Where $\mathrm{K}_{\text {нз }}$ - irrelevant cost factor in the range of 0 to $1, \sum_{H}$ - the total amount of irrelevant costs for the period; $\sum_{\mathrm{p}}$ the total amount of relevant costs for the period, excluding not won tenders.

The obtained coefficient of irrelevance for the value of "0" indicates that to get the tenders, organization does not carry out any preliminary costs, i.e. it is the effective expenditure of resources or there were no lost tenders at all; for value of "1" the irrelevant costs become absolute, that is, inefficient operation of the company. This ratio can be calculated for any period and on any date, provided that there is a tender, in which the organization is involved. Correlating the obtained for the same time intervals factors one may make conclusions about effectiveness of administrative decisions made by management.

When the index tends to unit, the organization has the possibility associated with transition to a new, more expensive level of orders execution. In this case, along with the coefficient of irrelevant costs it is also necessary to apply the profitability ratio of tenders, which is calculated as the ratio of income (revenue) to the amount of relevant and irrelevant costs. Thus, in Table 3 tender № 1 allowed us to get income of 90 thou rubles, tender number 2 - 520 thou rubles. For this, coefficient of irrelevant costs of tender number 2 is: $\mathrm{K}_{\text {нз }}=710(100+710)=0.87$, which is higher than the similar indicator calculated for tender number one, the irrelevant costs and imputed loss of which were included in the cost of tender number 2 . However, the profitability ratio of tenders indicates that the implementation of loss-making order was not a mistake:

$$
\text { Крен } 1=90:(100+350)=0,2 \text {, or } 20 \% \text {. }
$$


$K_{\text {рен } 2}=520:(100+710)=0,642$, or $64,2 \%$.

Thus, the profitability of tender number 2 even with taking into account the cost of tender № 1 has increased by more than $40 \%$, thus reducing the overall cost of non-return expenditures of organization from 350 thou rubles up to 290 thou rubles. Further, if the management of appraising company could find a few more orders, changing, thus, the tend to accumulate irrelevant costs and "output in plus " will be possible, i.e. profits from participation in implementation of orders obtained in tenders $[4,8,11]$.

In our view, the organizations involved in a large number of tenders should allocate levels of orders execution, based on the volume and cost of work, and closely monitor so that the total irrelevant costs accrued for tenders of the same level, did not "pass" in the cost of orders of the next level. The reason is that the greater is the level of execution cost of order, the lower is the number of orders themselves at this level and so they are more important for the organization in terms of contribution to overall profits; and hence the influence of irrelevant cost factor increases. In other words, $\mathrm{K}_{\text {нз }}$ of the first level of 0.5 is not the same as $\mathrm{K}_{\text {нз }}$ of 0.5 of the third level. As for the last level of orders execution, the coefficient of irrelevance of more than 0.5 , is generally not allowed to, because the next level, by which the non-return costs could be compensated does not exist, and the previous levels are not able to provide the necessary amount of revenue. From our experience of working in the field of appraising business, we have been developed the following gradation of levels of orders execution for tenders (Table 2).

Table 2. Grouping of orders as to levels based on cost criterion

\begin{tabular}{|l|c|c|c|c|}
\hline \multicolumn{2}{|c|}{ level of performance of order } & \multirow{2}{*}{ Number of orders executed } & \multicolumn{2}{c|}{ maximum revenue } \\
\cline { 1 - 2 } amount in thou rubles & gradation & & in thous. rub. & in \% \\
\hline Up to 50 & I & 30 & 1500 & 3,93 \\
\hline From 50 to 100 & II & 22 & 2200 & 5,76 \\
\hline From 100 to 500 & III & 9 & 4500 & 11,78 \\
\hline From 500 to 2000 & IV & 5 & 10000 & 26,18 \\
\hline From 2000 to 10000 & V & 2 & 20000 & 52,36 \\
\hline \multicolumn{2}{|c|}{ Total } & 38200 & 100,00 \\
\hline
\end{tabular}

Thus, achieving the value "1" by coefficient of irrelevance (which means no orders) at the first level of their performance reduces revenue of the company by $3.93 \%$. At the fifth level, represented only by two orders, the maximum allowed percent indicator is just over 50\%, i.e. accumulation of irrelevant expenditures for the order with cost up to 10,000 rubles., can be covered by performance of the same second order. Let us specify that we mean maximum values of indicators.

The management of appraising company should analyze information about all tenders - by total participation in them and, first of all, to analyze the level and dynamics of prices offered by competitors [6, 9]. This will set out the best way to combine the mentioned relevant approach to the management of tender costs, setting the lower (breakeven) price limit and approach based on analysis of competitors' prices to ensure finding the upper limit. Within this price range for the organization "a room for maneuver" appears in terms of setting the final price level. The possibility to analyze competitors' prices appears during announcement of the results of tender, in which participants are given the announced prices and the place, which each of the participants took, and the first place is given to the winner. As a result, one can identify the approximate amount of discount that each of the participants is usually ready to give.

Let us consider a situation, in which a decision to participate in a particular tender and set a price for it is produced. Table 5 provides data on the costs associated with the execution of orders. We see that in terms of the level of resources spent the orders are not of the same type, i.e. among them may be the priority, which the appraising firm would like to get, and the others.

In the process of determining which of the tenders is a priority, and which can be ignored, it is necessary to take into account that irrelevant costs in the amount of $6 \sum \mathrm{HPZ}$ thou rubles accumulated in three tenders are unchangable and should be covered by one of the tenders.

As for the value of relevant costs, they are specific for each of the tender due to different geographical location, amount of works executed, distance from city and other factors, and therefore will be the basis for pricing. It is necessary to find the marginal income rate (see formula (2)), representing the difference between the estimated cost of the order and the level of relevant costs $[3,10]$.

$\left(\left(\mathrm{B}^{\mathrm{i}}-\mathrm{discount}^{\mathrm{i}}\right)-\sum \mathrm{P} 3^{\mathrm{i}}\right)-6 \sum \mathrm{HPZ}=\mathrm{MD}^{\mathrm{i}}-6 \sum \mathrm{HP} 3=\mathrm{P}^{\mathrm{i}}$,

where $B$-the highest price of the order (excluding VAT) set by the organizer of the tender; (B -discount) - the estimated price of the order (excluding VAT), the claimed valuation firm in taking part in the tender; P3 - the value of 
relevant costs associated with the implementation of the order in case of victory in the tender; MD profit margin of the order, which is calculated as the difference between the estimated cost of the order (excluding VAT) and the relevant costs for the same order, HPZ - the value of irrelevant costs associated with taking part in tenders, $\mathrm{P}$ - profits derived from the performance of the order, $i$ - form of the tender, the amount of which is taken in the range of $1 \ldots n$.

Indicators that affect the profit level of the order are: "B", tending to the maximum, and "P3", tending to the minimum. Maximization of "B" depends on which of the five levels the specific order is (see Table. 4). The higher is the price of the order designated by the organizers of the tender in documentation, the greater will be the value of "B discount" offered by the appraising firm and its competitors. In addition to this, increase in profits is facilitated by minimization of "P3", for example, due to closeness of appraising company from the place of appraisment and other factors. The index " HPZ ", as already noted, is unchangable, so it cannot affect the amount of profit (P). Thus, the tender for which the index of marginal revenue is higher, will be a priority.

\section{Conclusion}

Thus, the proposed in this paper relevant approach to decision-making regarding participation or non-participation of appraising organization in the tender or group of mutually related tenders allows us to solve complex problems associated with determining the economically reasoned levels of costs for execution of contracts for tenders, and, respectively, with reasonable pricing for different conditions of victory. However, the techniques in this article for systematizing the relevant and irrelevant costs in the context of each of the tender may be used only for small amounts of activity or in conditions of adapted for tender activities software product added with required directories, management accounts, reports, as well as calculation algorithms for implementation of relevant approach.

\section{References}

Novenkova A.Z., Gafurov I.R., Kalenskaya N.V. Marketing of Educational Services: Research on Service Providers Satisfaction /I Procedia Economics and Finance, Volume 5, 2013, Pages 368-376.

Shaidullin R.N., Ulesov D.V., Shigabieva A.M. and Safiullin L.N. Innovative Infrastructure in Post-Industrial Society/l World Applied Sciences Journal, 27(13), 2013, pp. 180-183.

Safiullin L.N., Ismagilova G.N., Safiullin N.Z., Bagautdinova N.G. The development of welfare theory in conditions of changes in the quality of goods and services (2012) World Applied Sciences Journal 18 (Special Issue of Economics), pp. 144-149.

Drury C., 1998. Introduction to managerial and cost accounting: a manual for schools / K. Drury, trans. from English., ed. ND Eriashvili 3rd ed., Rev. and add. - M.: Audit, Unity, 783 p.

Scone T., 1997. Management Accounting / T. Scone, translated from Eng. Ed. N.D.Eriashvili. - M.: Audit, Unity, 179 p.

Safiullin L.N., Ismagilova G.N., Gallyamova D.Kh., Safiullin N.Z. 2013. Consumer benefit in the competitive market // Procedia Economic and finance. Volume 5, pp. 667-676 (DOI: 10.1016/S2212-5671(13)00078-6).

Horngren, C., 2007. Management Accounting, / Charles Horngren, G. Foster, S. Datar, trans. from English. - 10th Edition - St.: Peter, 2007. - 1008 p. (in Russian)

Safiullin L.N., Gafurov I.R., Safiullin N.Z., Bagautdinova N.G. Distribution and product selection under uncertainty / Recent Trends in Social and Behaviour Sciences - Proceedings of the 2nd International Congress on Interdisciplinary Behavior and Social Sciences 2013, ICIBSoS 2013 PP. $309-313$.

Balachandran, B.V. Interface between ABC / M requirements and multi-dimensional databases / BV Balachandran, K.S. Sundar / / Cost Management. - November / December. - P. 33-39.

Graham, Francis, 2000. Value-based management in practice / Francis Graham, Minchington Clare / / Management Accounting. February. - P. 46-47.

Bagautdinova, N.G., Novenkova, A.Z., Sarkin, A.V. Quality management system formulation and implementation as a factor of enhancement of the university role in the local development // World Applied Sciences Journal, 27(13), 2013, 38-42. 